\title{
Nothing to smile about
}

This article was published in the following Dove Press journal:

Neuropsychiatric Disease and Treatment

23 October 2014

Number of times this article has been viewed

\author{
Maria Luca' \\ Antonina Luca ${ }^{2}$ \\ Carmelo Maria Augusto \\ Vittorio Grasso ${ }^{3}$ \\ Carmela Calandra' \\ 'Department of Medical and Surgery \\ Specialties, Psychiatry Unit, University \\ Hospital "Policlinico-Vittorio \\ Emanuele" of Catania, Sicily, Italy; \\ 2Department "GF Ingrassia", Section \\ of Neuroscience, University Hospital \\ "Policlinico-Vittorio Emanuele" of \\ Catania, Sicily, Italy; ${ }^{3}$ Department of \\ Medical and Surgery Specialties, Dental \\ Unit, University Hospital "Policlinico- \\ Vittorio Emanuele" of Catania, Sicily, \\ Italy
}

Background: Several studies have demonstrated the high incidence of periodontal disorders among patients suffering from mental illnesses, probably because of self-care impairment, the difficult financial conditions, and the lack of motivation. The primary aim of this study was to evaluate the impact of depression and alexithymia on periodontal status. Due to the influence of personality traits on behavior in general, the secondary aim of our study was to investigate the possible impact of personality disorders on dental status.

Methods: Patients with major depression (DP) referred to our psychiatry unit and healthy individuals (controls) were consecutively enrolled during the period April 2012-September 2012. All the participants to the study underwent a psychiatric evaluation (through questionnaires investigating the presence of depression, anxiety, personality disorders, and alexithymia) and a dental examination through the following indexes: plaque index, gingival index, simplified oral hygiene index, periodontal index.

Results: Fifty DP (aged 56.7 \pm 15.2 years) and 40 controls (aged 56.1 \pm 15.9 years) were enrolled in the study. DP showed a worse oral hygiene status. In particular, statistically significant differences were found when comparing DP and controls in terms of plaque index, simplified oral hygiene index, gingival index, periodontal index, and oral health impact profile. In addition, periodontal health was found to be negatively related to the severity of depression and the presence of alexithymia. The strength of association between depression and dental indexes was reduced after adjusting for the other psychiatric variables (alexithymia and personality disorders) and was confirmed only for oral health impact profile.

Conclusion: Psychiatric variables seem to affect the patients' periodontal status; due to the high frequency of dental problems, patients suffering from mental illnesses should be referred to the oral health services for evaluation.

Keywords: depression, alexithymia, oral health, dental health, oral health-related quality of life, dental indexes

\section{Background}

Poor oral health is a major public problem all over the world. The impact of oral disturbances on individuals and communities are notable, particularly if the consequences on oral function and quality of life, as well as the societal costs, are taken into consideration. ${ }^{1}$ Oral diseases affect systemic health and social functioning of the patients; the pain, the negative esthetic impact, and the discomfort has important repercussions on public and private relationships. ${ }^{2,3}$ Furthermore, recent studies have suggested that periodontitis could be considered as a risk factor for cognitive decline. ${ }^{4}$ Several factors, such as nutritional habits, hygiene, tobacco and alcohol use, stress, and traumatic events exert a role in the occurrence of oral health problems. ${ }^{5}$ In light of the risk factors, the high incidence of oral disorders all over the world, particularly among disadvantaged populations, needs no explanation. ${ }^{6}$ Oral health should be interpreted as an issue pertaining general health and its promotion should not be limited to the dentistry field. In everyday medical practice, while performing
Correspondence: Carmela Calandra Department of Medical and Surgery Specialties, Psychiatry Unit, University Hospital "Policlinico-Vittorio Emanuele" of Catania, Via Santa Sofia 78, 95I00 Catania, Sicily, Italy Tel/Fax +390953782636

Email c.calandra@unict.it 
the general examination, proper attention must be given also to oral health; this could facilitate the achievement of the ambitious goal proposed by the World Health Organization: the improvement of oral health status in the world. ${ }^{7}$ In addition, special attention should be dedicated to the most vulnerable patients, who tend to adopt bad habits and would benefit from simple oral hygiene advice. Among the at-risk categories, patients suffering from mental illnesses are certainly in need of consideration. Several studies have demonstrated the high incidence of periodontal problems among psychotic patients, probably because of self-care impairment, the side effects of many psychotropic medications, the difficult financial conditions, and the lack of motivation. ${ }^{8,9}$

The care of these patients should not be limited to the psychopathological aspects; their unhealthy habits cannot be passively accepted as a natural consequence of their psychiatric illness. Moreover, the problem of poor oral hygiene is not limited to the patients suffering from severe mental disorders and presenting limited management skills, but pertains also to patients affected by mild psychiatric disturbances. Although to date there are no systematic studies on the prevalence of depression in dental patients, an association between stress, depression, and chronic forms of periodontal disease has been documented. ${ }^{10}$ Major depression in the general population has a lifetime prevalence ranging from $10 \%$ to $15 \%{ }^{11}$ with an increased rate in females. ${ }^{12}$

Patients with major depression (DP) are notoriously poorly dedicated to their oral hygiene and tend to follow a self-destructive lifestyle in terms of nutrition and voluptuary habits. ${ }^{13}$ This self-destructive behavior exposes DP to the occurrence of oral health problems that worsen their quality of life through the occurrence of psychological disturbances; in fact, oral clefts, missing teeth, severe malocclusion, and severe caries are associated with feelings of embarrassment, withdrawal, anxiety, and insomnia ${ }^{3,14}$ Moreover, depression is frequently accompanied by alexithymia, a personality trait involving difficulties in emotional regulation (difficulties in identifying feelings, difficulties in describing feelings, and externally oriented thinking). ${ }^{15,16}$ Alexithymia has been found to be related to a poor oral health-related quality of life and dental fear; ${ }^{17,18}$ the latter could lead to the avoidance of oral health services. The primary aim of our study was to evaluate the impact of depression and alexithymia on periodontal status. Due to the influence of personality traits on behavior in general, the secondary aim of our study was to investigate the possible impact of personality disorders (PDs) on dental status.

\section{Methods}

DP (outpatients) referred to our psychiatry unit for consultation were consecutively enrolled in the study. Healthy subjects (controls) with no neurological or psychiatric disorders were recruited from the general population (relatives of university students, hospital employees, acquaintances of the research team) during the period April 2012-September 2012. No form of compensation was given to the participants. Individuals suffering from cancer and acquired or congenital maxillofacial pathologies were excluded from the study. The study was approved by the local ethics committee of the University Hospital "Policlinico-Vittorio Emanuele" of Catania and each individual signed a written informed consent. All the enrolled subjects filled in a questionnaire pertaining to demographic data, voluptuary habits (tobacco smoking, coffee, alcohol, and drugs abuse), oral hygiene (frequency of teeth-brushing, type of toothbrush, use of mouthwash, use of flossing, etc), use of partial dentures or being edentulous. Smokers were divided into three groups according to the number of cigarettes smoked per day, according to previous studies: mild (less than 15 cigarettes/day), moderate (from 15 to 24 cigarettes/day), and heavy (25 or more cigarettes/day) smokers. ${ }^{19}$ Drinkers were divided into three groups according to the quantity of alcohol consumption: mild (from 1 to $14.9 \mathrm{~g} /$ day), moderate (from 15 to $29.9 \mathrm{~g} /$ day), and heavy drinkers (30 or more g/day). ${ }^{20}$ The presence of diabetes was recorded. As for DP, the presence of previous depressive episodes and suicidal ideation during the current episode were recorded.

All the participants underwent a psychiatric evaluation through the following questionnaires: 1) the Hamilton Rating Scale for Depression: it is a reliable tool consisting of 21 items for the assessment of depression. The severity of depression is evaluated as follows: $\geq 25$ severe depression; 18-24 moderate depression; 8-17 mild depression; $\leq 7$ absence of depression..$^{21,22}$ As to controls, the test was administered in order to exclude the presence of depressive symptoms. 2) The Hamilton Rating Scale for Anxiety: it is a validated and reliable tool consisting of 14 items for the assessment of anxiety. A total score $\geq 18$ was considered pathological. ${ }^{23,24} 3$ ) The 20 -item Toronto Alexithymia Scale: it is a reliable instrument consisting of three subscales assessing alexithymia: subscale I assessing the difficulty in identifying feelings; subscale II assessing the difficulty in describing feelings; subscale III assessing externally oriented thinking and the lack of introspective capacities. A total score of 61 and above indicates an alexithymic state. Scores between 51 and 60 indicate a condition of borderline alexithymia. ${ }^{25,26} 4$ ) The Structured Clinical Interview for 
DSM-IV Axis II Personality Disorders: it is a validated scale investigating the presence of PDs. It considers the eleven DSM-IV PDs (including PD not otherwise specified) and the appendix categories depressive $\mathrm{PD}$ and passive-aggressive PD. ${ }^{27,28} 5$ ) The oral health impact profile (OHIP-14): it is a validated scale ${ }^{29}$ assessing the burden of oral health status on the quality of life through 14 items. The total OHIP-14 score ranges from 0 to 56 . The higher the OHIP-14 total score, the worse the oral health-related quality of life is..$^{30,31}$ Then, all the participants (except the fully edentulous ones) underwent a dental examination performed by a dentist evaluating six selected teeth (maxillary right first molar, maxillary right lateral incisor, maxillary left first bicuspid, mandibular left first molar, mandibular left lateral incisor, mandibular right first bicuspid). The following indexes have been calculated: 1) plaque index (PI): it is a validated index designed to estimate the presence of plaque. ${ }^{32}$ The total score for each tooth ranges from 0 to 3 . The scores of each tooth are then added together and the value is divided by six in order to obtain the score of the patient. Four ratings have been assigned to each patient: 0 excellent; from 0.1 to 0.9 good; from 1.0 to 1.9 fair, from 2.0 to 3.0 poor. ${ }^{33}$ ) Gingival index (GI): it is a validated and reliable inde ${ }^{34}$ designed to estimate different degrees of inflammation in the marginal gingiva. The total score ranges from 0 to 3 , according to the severity of the inflammation. The scores of each tooth are added together and the value is divided by six in order to obtain the score of the patient. Four ratings have been assigned to each patient: 0 excellent; from 0.1 to 1.0 good; from 1.1 to 2.0 fair; from 2.1 to 3.0 poor. ${ }^{35} 3$ ) Simplified oral hygiene index (OHI-S): it is a good instrument that evaluates the level of oral hygiene. The total score ranges from 0 to 6 . The total score is the sum of the debris index (that ranges from 0 to 3 ) and the calculus index (that ranges from 0 to 3 ). The following ratings have been assigned to each patient: from 0 to 1.2 good, from 1.3 to 3.0 fair, from 3.1 to 6.0 poor. $^{36} 4$ ) Periodontal index (PeI): it is a good index intended to estimate deeper periodontal disease by investigating the presence of gingival inflammation and its severity, the pocket formation, and masticatory function. The total score ranges from 0 to 8 as follows: from 0 to 0.2 normal (no inflammation), from 0.3 to 0.9 simple gingivitis (inflammation, not circumscribing the tooth), from 1.0 to 1.9 periodontal disease at early stage (inflammation circumscribing the tooth), from 2.0 to 4.9 mild periodontal disease (gingivitis with pocket formation), from 5.0 to 8.0 severe periodontal disease (tissue destruction with loss of function). Five ratings have been assigned to each patient: excellent (0-0.2), good (0.3-0.9), fair (1.0-1.9), poor (2.0-4.9), very poor $(5.0-8.0){ }^{37}$

\section{Statistical analysis}

All data analyses were generated using the Statistical Package for Social Sciences for Windows (version 13.0 for Windows; SPSS Inc., Chicago, IL, USA). Quantitative variables were described using mean and standard deviation. The difference between means and the difference between proportions was evaluated by the $t$-test and the chi-square test respectively. In case of not a normal distribution, appropriate nonparametric tests were performed. Only values of $P<0.05$ were considered statistically significant.

A multivariate approach was then adopted in order to investigate the independent effect of a risk or protective factor after adjustment for the parameters significantly associated with the outcome at the univariate analysis. Unconditional logistic regression analysis was performed and we calculated odds ratio (OR), 95\% confidence interval (CI), and $P$-value (two-tailed test, $\alpha=0.05$ ) for each variable.

\section{Results}

\section{General characteristics of the sample}

Fifty-three DP were eligible for the study. Three of them refused to participate. Then, 50 DP (15 men and 35 women; aged 56.7 \pm 15.2 years) and 40 controls ( 16 men and 24 women; aged 56.1 \pm 15.9 years) were enrolled in the study. No significant differences in age, sex, and years of schooling (9.8 \pm 3.6 years among DP versus $9.4 \pm 4.4$ years among controls) were recorded when comparing DP and controls. No significant differences in terms of voluptuary habits and diabetes were found between the two groups. No heavy drinkers were found. Fourteen percent of the DP presented mild depression, 38\% moderate depression, and 48\% severe depression. Seventy-two percent of the DP presented anxiety versus $17.5 \%$ of the controls (OR 12.12, 95\% CI 4.35-33.71; $P<0.001)$. In addition, $58 \%$ of the DP were alexithymic versus $7.5 \%$ of the controls (OR 35.04, 95\% CI 8.4-145.44; $P<0.001)$. Twenty-six percent of DP presented a condition of borderline alexithymia versus $22.5 \%$ of the controls (OR 5.89, 95\% CI 1.81-19.13; $P<0.001)$. Out of the 50 interviewed DP, 43 presented at least one PD at the Structured Clinical Interview for DSM-IV Axis II Personality Disorders, while only 14 controls were affected by at least one PD. The frequency of PDs among DP was as follows: absence of PD, seven (14\%); borderline PD, seven (14\%); histrionic PD, four ( $8 \%$ ); narcissistic PD, one (2\%); obsessive-compulsive PD, 12 (24\%); paranoid $\mathrm{PD}$, three (6\%); avoidant $\mathrm{PD}$, four $(8 \%)$; depressive PD, two (4\%); dependent PD, two (4\%); passive-aggressive $\mathrm{PD}$, zero $(0 \%)$, not otherwise specified (intending more than one PD) PD, eight (16\%). The frequency of PDs among 
controls was as follows: absence of PD, 26 (65\%); borderline PD, zero ( $0 \%$ ); histrionic PD, two (5\%); narcissistic PD, two (5\%); obsessive-compulsive $\mathrm{PD}$, three $(7.5 \%)$; paranoid $\mathrm{PD}$, three (7.5\%); avoidant PD, one (2.5\%); depressive PD, zero $(0 \%)$; dependent $\mathrm{PD}$, zero (0\%); passive-aggressive $\mathrm{PD}$, one (2.5\%); not otherwise specified PD, two (5\%). The only PD that presented a statistically significant difference between DP and controls was the obsessive-compulsive PD, recorded in $12(24 \%)$ DP and in three (7.5\%) controls (OR 14.85, 95\% CI 3.26-67.63, $P<0.001)$. For more details see Table 1.

\section{Periodontal status: DP versus controls}

As to periodontal status, no significant differences in terms of frequency of teeth-brushing, type of toothbrush, use of mouthwash, flossing, use of partial dentures, being edentulous or not, were recorded when comparing DP and controls. On the contrary, significant differences were found when considering PI: $22 \%$ of DP versus $47.5 \%$ of controls presented a fair PI (OR 13.93, 95\% CI 2.77-69.88, $P=0.001$ ); 38\% of DP versus $5 \%$ of controls had a poor PI (OR 36.1, 95\% CI 6.21-209.5, $P=0.001$ ). In addition, $44 \%$ of DP versus $12.5 \%$ of controls presented a poor OHI-S (OR 4.4, 95\% CI 1.31-14.7, $P=0.01$ ). Thirty-four percent of DP presented a fair/poor GI versus $22.5 \%$ of controls (OR 3.1, 95\% CI 1.01-9.33, $P=0.04$ ). Also, the PeI score was significantly different between the two groups: $42 \%$ of DP versus $20 \%$ of controls presented a fair/ poor PeI (OR 4.43, 95\% CI 1.42-13.75, $P=0.009$ ). As to the OHIP-14, the DP presented a mean score of $17.3 \pm 13.6$ versus the 3.9 \pm 5.3 registered among the controls (OR 1.16, 95\% CI 1.08-1.25, $P<0.001)$. For more details, see Table 1.

\section{Multivariate approach}

A multivariate approach was adopted in order to investigate the independent effect of depression on periodontal status after adjustment for the parameters significantly associated with the outcome at the univariate analysis. Since few individuals were heavy smokers, a single category was created (moderate/heavy). The unconditional logistic regression performed for each dental index (OHIP-14, PI, GI, OHI-S, and PeI) adjusting for age, sex, smoking, alexithymia, anxiety, and PD confirmed only the strength of the association between depression and OHIP-14 found at the univariate analysis (adjusted OR 1.19, 95\% CI 1.06-1.34, $P=0.002$ ).

\section{Periodontal status and severity of depression}

When considering the severity of depression, no significant differences in terms of OHIP-14 were found comparing the three levels (mild, moderate, and severe). On the contrary, there were significant differences pertaining to the frequency of excellent PI (57.1\% in DP suffering from mild depression versus $0 \%$ in DP with moderate depression versus $4.2 \%$ in DP with severe depression; $P<0.05)$, excellent GI ( $85.7 \%$ in mild depression versus $21.1 \%$ in moderate depression versus $20.8 \%$ in severe depression; $P<0.05)$, good OHI-S $(85.7 \%$ in mild depression versus $26 \%$ in moderate depression versus $16.7 \%$ in severe depression; $P<0.05)$ and excellent PeI $(85.7 \%$ in mild depression versus $15.8 \%$ in moderate depression and $25 \%$ in severe depression; $P<0.05$ ). For more details, see Table 2.

\section{Periodontal status and alexithymia}

With regards to the correlations between periodontal status and alexithymia, $55.2 \%$ of DP with alexithymia presented a poor PI score versus $12.5 \%$ of DP without alexithymia and $15.4 \%$ of DP with borderline alexithymia $(P<0.05)$. A significant difference was also found when considering PeI: only $17.2 \%$ of DP with alexithymia presented an excellent PeI, versus $53.8 \%$ of DP with borderline alexithymia and $37.5 \%$ of DP without alexithymia $(P<0.05)$. No other significant differences were found when comparing the three groups (DP with/without alexithymia, DP with borderline alexithymia). For more details, see Table 3. No correlations between status and the other variables evaluated in this study (eg, anxiety and personality) were found.

\section{Discussion}

Poor oral health is a silent epidemic with considerable consequences on the quality of life. ${ }^{38}$ Previous studies demonstrated poorer oral health in patients with mental disorders. ${ }^{39,40}$ Our results support these literature data. In our study there were no significant differences in terms of age, voluptuary habits, and hygiene between DP and controls; however, when comparing the two groups, statistically significant differences pertaining to oral health were found. In particular, DP presented a statistically significant worse oral condition in terms of: OHIP-14, PI, GI, PeI, and OHI-S. Few studies have specifically examined the relationship between depression and oral health. Some studies reported that depression was significantly associated with periodontal disease, as measured by clinical attachment loss or alveolar bone loss and with toothless and, in general, with a nonuse of oral health services. ${ }^{11,41,42}$ Psychiatrists and dentists must strongly fight against this maladaptive habit. From an interdisciplinary point of view, patients should be referred to the centers for mental/dental health. 
Table I Social and psychological characteristics of the sample

\begin{tabular}{|c|c|c|c|c|c|c|c|}
\hline & \multicolumn{2}{|c|}{$D P(n=50)$} & \multicolumn{2}{|c|}{ Controls $(n=40)$} & \multirow[t]{2}{*}{ OR } & \multirow[t]{2}{*}{$95 \% \mathrm{Cl}$} & \multirow[t]{2}{*}{$P$-value } \\
\hline & $\mathbf{N}$ & $\%$ & $\mathbf{N}$ & $\%$ & & & \\
\hline Age (mean $\pm S D)$ & $56.7 \pm 15.2$ & & $56.1 \pm 15.9$ & & 1 & $0.98-1.03$ & 0.853 \\
\hline \multicolumn{8}{|l|}{ Sex } \\
\hline Women & 35 & 70 & 24 & 60 & I & & \\
\hline Men & 15 & 30 & 16 & 40 & 0.64 & $0.27-1.54$ & 0.322 \\
\hline \multicolumn{8}{|l|}{ Depression } \\
\hline Absent & 0 & 0 & 40 & 100 & & & \\
\hline Mild depression & 7 & 14 & 0 & 0 & & & \\
\hline Moderate depression & 19 & 38 & 0 & 0 & & & \\
\hline Severe depression & 24 & 48 & 0 & 0 & & & \\
\hline \multicolumn{8}{|l|}{ Marital status } \\
\hline Married (reference) & 29 & 58 & 23 & 46 & I & & \\
\hline Singles & 8 & 16 & 14 & 28 & 0.45 & $0.16-1.26$ & 0.131 \\
\hline Divorced/widowers & 13 & 26 & 3 & 6 & 3.43 & $0.87-|3.5|$ & 0.07 \\
\hline \multicolumn{8}{|l|}{ Tobacco } \\
\hline Non smokers (reference) & 33 & 66 & 32 & 80 & I & & \\
\hline Mild smokers & 8 & 16 & 6 & 15 & 1.29 & $0.4-4.14$ & 0.665 \\
\hline Moderate/heavy smokers & 9 & 18 & 2 & 5 & 4.36 & $0.87-21.77$ & 0.07 \\
\hline \multicolumn{8}{|l|}{ Coffee } \\
\hline No consumption & 16 & 32 & 7 & 17.5 & I & & \\
\hline Consumption of $<3$ cups/day & 28 & 56 & 25 & 62.5 & 0.49 & $0.17-1.38$ & 0.17 \\
\hline Consumption of 3 or more cups/day & 6 & 12 & 8 & 20 & 0.32 & $0.08-1.30$ & 0.11 \\
\hline \multicolumn{8}{|l|}{ Alcohol } \\
\hline No consumption (reference) & 40 & 80 & 29 & 72.5 & I & & \\
\hline Mild consumption & 5 & 10 & 9 & 22.5 & 0.4 & $0.12-1.32$ & 0.13 \\
\hline Moderate consumption & 5 & 10 & 0 & 0 & 1.81 & $0.32-10$ & 0.49 \\
\hline Diabetes & 13 & 26 & 5 & 12.5 & 2.45 & $0.79-7.61$ & 0.11 \\
\hline Cocaine & 3 & 6 & 0 & 0 & 5.97 & $0.3-119$ & 0.42 \\
\hline Anxiety & 36 & 72 & 7 & 17.5 & 12.12 & $4.35-33.71$ & $<0.001$ \\
\hline \multicolumn{8}{|l|}{ Alexithymia } \\
\hline Absent (reference) & 8 & 16 & 28 & 70 & I & & \\
\hline Borderline alexithymia & 13 & 26 & 9 & 22.5 & 5.89 & $1.81-19.13$ & $<0.001$ \\
\hline Present & 29 & 58 & 3 & 7.5 & 35.04 & $8.4-145.44$ & $<0.001$ \\
\hline \multicolumn{8}{|l|}{ Personality disorders } \\
\hline Absent (reference) & 7 & 14 & 26 & 65 & I & & \\
\hline Obsessive-compulsive & 12 & 24 & 3 & 7.5 & 14.85 & $3.26-67.63$ & $<0.001$ \\
\hline Others & 31 & 62 & 11 & 27.5 & 10.46 & $3.54-30.57$ & $<0.001$ \\
\hline Suicidal ideation & 12 & 24 & 0 & 0 & 0.96 & $0.4 I-2.24$ & 0.93 \\
\hline \multicolumn{8}{|l|}{ Frequency of teeth-brushing } \\
\hline 2 times/day or less (reference) & 37 & 74 & 29 & 72.5 & I & & \\
\hline 3 or more times/day & 13 & 26 & II & 27.5 & 0.92 & $0.36-2.36$ & 0.87 \\
\hline \multicolumn{8}{|l|}{ Type of toothbrush } \\
\hline Manual (reference) & 49 & 98 & 37 & 92.5 & I & & \\
\hline Electric & 1 & 2 & 3 & 7.5 & 0.25 & $0.02-2.51$ & 0.24 \\
\hline Use of mouthwash & 8 & 16 & 11 & 27.5 & 0.5 & $0.17-1.40$ & 0.18 \\
\hline Flossing & 2 & 4 & 5 & 12.5 & 0.29 & $0.05-1.59$ & 0.15 \\
\hline Dentures & 20 & 40 & 9 & 22.5 & 2.29 & $0.90-5.83$ & 0.08 \\
\hline Edentulous & 3 & 6 & 2 & 5 & 1.21 & $0.19-7.62$ & 0.83 \\
\hline OHIP-I4 (mean \pm SD) & $17.3 \pm 13.6$ & & $3.9 \pm 5.3$ & & 1.16 & $1.08-1.25$ & $<0.001$ \\
\hline \multicolumn{8}{|l|}{$\mathrm{PI}$} \\
\hline Excellent (reference) & 5 & 10 & 19 & 47.5 & I & & \\
\hline Good & 12 & 24 & 14 & 35 & 3.25 & $0.93-11.39$ & 0.06 \\
\hline Fair & II & 22 & 3 & 7.5 & 13.93 & $2.77-69.88$ & 0.001 \\
\hline Poor & 19 & 38 & 2 & 5 & 36.1 & $6.21-209.5$ & 0.001 \\
\hline Not applicable & 3 & 6 & 2 & 5 & 5.7 & $0.73-43.94$ & 0.094 \\
\hline
\end{tabular}


Table I (Continued)

\begin{tabular}{|c|c|c|c|c|c|c|c|}
\hline & \multicolumn{2}{|c|}{ DP $(n=50)$} & \multicolumn{2}{|c|}{ Controls $(n=40)$} & \multirow[t]{2}{*}{ OR } & \multirow[t]{2}{*}{$95 \% \mathrm{Cl}$} & \multirow[t]{2}{*}{$P$-value } \\
\hline & $\overline{\mathbf{N}}$ & $\%$ & $\overline{\mathbf{N}}$ & $\%$ & & & \\
\hline \multicolumn{8}{|l|}{$\overline{\mathrm{OHI}}-\mathrm{S}$} \\
\hline Good (reference) & 15 & 30 & 15 & 37.5 & I & & \\
\hline Fair & 10 & 20 & 18 & 45 & 0.55 & $0.19-1.59$ & 0.27 \\
\hline Poor & 22 & 44 & 5 & 12.5 & 4.4 & $1.31-14.7$ & 0.01 \\
\hline Not applicable & 3 & 6 & 2 & 5 & 1.5 & $0.21-10.30$ & 0.68 \\
\hline \multicolumn{8}{|l|}{ GI } \\
\hline Excellent (reference) & 15 & 30 & 19 & 47.5 & I & & \\
\hline Good & 15 & 30 & 12 & 30 & 1.58 & $0.57-4.37$ & 0.37 \\
\hline Fair/Poor & 17 & 34 & 9 & 22.5 & 3.1 & $1.01-9.33$ & 0.04 \\
\hline Not applicable & 3 & 6 & 0 & 0 & 1.9 & $0.28-12.86$ & 0.51 \\
\hline \multicolumn{8}{|l|}{ Pel } \\
\hline Excellent (reference) & 15 & 30 & 19 & 47.5 & I & & \\
\hline Good & II & 22 & 13 & 32.5 & 1.07 & $0.37-3.06$ & 0.89 \\
\hline Fair/Poor & 21 & 42 & 8 & 20 & 4.43 & $1.42-13.75$ & 0.009 \\
\hline Not applicable & 3 & 6 & 0 & 0 & 1.9 & $0.28-12.86$ & 0.51 \\
\hline
\end{tabular}

Note: Bold $P$-values are statistically significant.

Abbreviations: DP, patients with major depression; N, number; OR, odds ratio; Cl, confidence interval; OHIP-I4, oral health impact profile; PI, plaque index; GI, gingival index; OHI-S, simplified oral hygiene index; Pel, periodontal index; SD, standard deviation.

Table 2 Oral hygiene habits and periodontal parameters according to depression severity

\begin{tabular}{|c|c|c|c|c|}
\hline & Mild depression $(n=7)$ & Moderate depression $(n=19)$ & Severe depression $(n=24)$ & $P$-value \\
\hline \multicolumn{5}{|c|}{ Frequency of teeth-brushing (n, \%) } \\
\hline$<2$ times per day & $5(71.4 \%)$ & $13(68.4 \%)$ & 19 (79.2\%) & ns \\
\hline 3 or more times per day & $2(28.6 \%)$ & $6(31.6 \%)$ & $5(20.8 \%)$ & ns \\
\hline \multicolumn{5}{|l|}{ Type of toothbrush (n, \%) } \\
\hline Manual toothbrush & 7 (100\%) & $19(100 \%)$ & $23(95.8 \%)$ & ns \\
\hline Electric toothbrush & $0(0 \%)$ & $0(0 \%)$ & I (4.2\%) & ns \\
\hline Use of mouthwash (n, \%) & ( $(14.3 \%)$ & $3(15.8 \%)$ & $4(16.7 \%)$ & ns \\
\hline Flossing $(\mathrm{n}, \%)$ & $0(0 \%)$ & $0(0 \%)$ & $2(8.3 \%)$ & ns \\
\hline Dentures (n, \%) & $2(28.6 \%)$ & $6(31.6 \%)$ & $12(50 \%)$ & ns \\
\hline Edentulous ( $\mathrm{n}, \%)$ & $0(0 \%)$ & $0(0 \%)$ & $3(12.5 \%)$ & ns \\
\hline OHIP-I4 (mean \pm SD) & $15.1 \pm 13.6$ & $15.6 \pm 14$ & $18.8 \pm 13.7$ & ns \\
\hline \multicolumn{5}{|l|}{$\mathrm{PI}(\mathrm{n}, \%)$} \\
\hline Excellent & $4(57.1 \%)^{*}$ & $0(0 \%)$ & I $(4.2 \%)^{*}$ & $<0.05$ \\
\hline Good & I (14.3\%)* & $10(52.6 \%)^{*}$ & I $(4.2 \%)^{*}$ & $<0.05$ \\
\hline Fair & I (I4.3\%) & $3(15.8 \%)$ & 7 (29.2\%) & ns \\
\hline Poor & I (I4.3\%) & $6(31.6 \%)$ & $12(50 \%)$ & ns \\
\hline Not applicable & $0(0 \%)$ & $0(0 \%)$ & $3(12.5 \%)$ & ns \\
\hline \multicolumn{5}{|l|}{$\mathrm{Gl}(\mathrm{n}, \%)$} \\
\hline Excellent & $6(85.7 \%)^{*}$ & $4(21.1 \%)^{*}$ & 5 (20.8\%)* & $<0.05$ \\
\hline Good & $0(0 \%)$ & $8(42.1 \%)$ & $7(29.2 \%)$ & ns \\
\hline Fair & I (I4.3\%) & $5(26.3 \%)$ & $6(25 \%)$ & ns \\
\hline Poor & $0(0 \%)$ & $2(10.5 \%)$ & $3(12.5 \%)$ & ns \\
\hline Not applicable & $0(0 \%)$ & $0(0 \%)$ & $3(12.5 \%)$ & ns \\
\hline \multicolumn{5}{|l|}{ OHI-S (n, \%) } \\
\hline Good & $6(85.7 \%)^{*}$ & $5(26.3 \%)^{*}$ & $4(16.7 \%)^{*}$ & $<0.05$ \\
\hline Fair & $0(0 \%)$ & $7(36.8 \%)$ & 3 (12.5\%) & ns \\
\hline Poor & ( (14.3\%) & 7 (36.8\%) & $14(58.3 \%)$ & ns \\
\hline Not applicable & $0(0 \%)$ & $0(0 \%)$ & $3(12.5 \%)$ & ns \\
\hline \multicolumn{5}{|l|}{ Pel $(n, \%)$} \\
\hline Excellent & $6(85.7 \%)^{*}$ & $3(15.8 \%)^{*}$ & $6(25 \%)^{*}$ & $<0.05$ \\
\hline Good & $0(0 \%)$ & $10(52.6 \%)^{*}$ & I $(4.2 \%)^{*}$ & $<0.05$ \\
\hline Fair & I (14.3\%) & $4(21.1 \%)$ & $12(50 \%)$ & ns \\
\hline Poor & $0(0 \%)$ & $2(10.5 \%)$ & $2(8.3 \%)$ & ns \\
\hline Very poor & $0(0 \%)$ & $0(0 \%)$ & - & \\
\hline Not applicable & $0(0 \%)$ & $0(0 \%)$ & 3 (I2.5\%) & ns \\
\hline
\end{tabular}

Notes: *Represents which variable is significant versus another with $P<0.05$. Bold $P$-values are statistically significant.

Abbreviations: OHIP-14, oral health impact profile; PI, plaque index; Gl, gingival index; OHI-S, simplified oral hygiene index; Pel, periodontal index; ns, not significant; $\mathrm{SD}$, standard deviation. 
Table 3 Oral hygiene habits, periodontal parameters, and alexithymia in DP

\begin{tabular}{|c|c|c|c|c|}
\hline & $\begin{array}{l}\text { Absence of } \\
\text { alexithymia }(n=8)\end{array}$ & $\begin{array}{l}\text { Borderline } \\
\text { alexithymia }(n=13)\end{array}$ & $\begin{array}{l}\text { Presence of } \\
\text { alexithymia }(n=29)\end{array}$ & $P$-value \\
\hline \multicolumn{5}{|c|}{ Frequency of teeth-brushing ( $\mathrm{n}, \%)$} \\
\hline$<2$ times per day & $6(75 \%)$ & $12(92.3 \%)$ & 19 (65.5\%) & ns \\
\hline 3 or more times per day & $2(25 \%)$ & $\mathrm{I}(7.7 \%)$ & 10 (34.5\%) & ns \\
\hline \multicolumn{5}{|l|}{ Type of toothbrush $(n, \%)$} \\
\hline Manual toothbrush & $8(100 \%)$ & $12(92.3 \%)$ & $29(100 \%)$ & ns \\
\hline Electric toothbrush & $0(0 \%)$ & $\mathrm{I}(7.7 \%)$ & $0(0 \%)$ & ns \\
\hline Use of mouthwash (n, \%) & I (I2.5\%) & $2(15.4 \%)$ & $5(17.2 \%)$ & ns \\
\hline Flossing (n, \%) & I (I2.5\%) & $0(100 \%)$ & I (3.4\%) & ns \\
\hline Dentures (n, \%) & $3(37.5 \%)$ & $5(38.5 \%)$ & 12 (4I.4\%) & ns \\
\hline Edentulous (n, \%) & $\mathrm{I}(12.5 \%)$ & I (7.7\%) & $\mathrm{I}(3.4 \%)$ & ns \\
\hline OHIP-I 4 (mean \pm SD) & $15.2 \pm 6.5$ & $15.5 \pm 1 \mid .3$ & $18.3 \pm 16$ & ns \\
\hline \multicolumn{5}{|l|}{$\mathrm{PI}(\mathrm{n}, \%)$} \\
\hline Excellent & I (I2.5\%) & $3(23.1 \%)$ & I (3.4\%) & ns \\
\hline Good & $4(50 \%)$ & $2(15.4 \%)$ & $6(20.7 \%)$ & ns \\
\hline Fair & $\mathrm{I}(12.5 \%)$ & $5(38.5 \%)$ & $5(17.2 \%)$ & ns \\
\hline Poor & I (I2.5\%)* & $2(15.4 \%)^{*}$ & $16(55.2 \%)^{*}$ & $<0.05$ \\
\hline Not applicable & I (I2.5\%) & I (7.7\%) & I (3.4\%) & ns \\
\hline \multicolumn{5}{|l|}{$\mathrm{GI}(\mathrm{n}, \%)$} \\
\hline Excellent & $4(50 \%)$ & $6(46.2 \%)$ & 5 (I7.2\%) & ns \\
\hline Good & $3(37.5 \%)$ & 2 (15.4\%) & $10(34.5 \%)$ & ns \\
\hline Fair & $0(0 \%)$ & $3(23.1 \%)$ & $9(3 \mid \%)$ & ns \\
\hline Poor & $0(0 \%)$ & I (7.7\%) & $4(13.8 \%)$ & ns \\
\hline Not applicable & I (I2.5\%) & I (7.7\%) & I (3.4\%) & ns \\
\hline \multicolumn{5}{|l|}{ OHI-S (n, \%) } \\
\hline Good & $4(50 \%)$ & $6(46.1 \%)$ & $5(17.3 \%)$ & ns \\
\hline Fair & $2(25 \%)$ & $2(15.4 \%)$ & $6(20.7 \%)$ & ns \\
\hline Poor & I (I2.5\%) & $4(30.8 \%)$ & 17 (58.6\%) & ns \\
\hline Not applicable & I (I2.5\%) & I (7.7\%) & I (3.4\%) & ns \\
\hline \multicolumn{5}{|l|}{ Pel $(n, \%)$} \\
\hline Excellent & 3 (37.5\%) & 7 (53.8\%)* & $5(17.2 \%)^{*}$ & $<0.05$ \\
\hline Good & $3(37.5 \%)$ & $3(23.1 \%)$ & $5(17.2 \%)$ & ns \\
\hline Fair & I (I2.5\%) & I (7.7\%)* & 15 (51.7\%)* & $<0.05$ \\
\hline Poor & $0(0 \%)$ & I (7.7\%) & $3(10.3 \%)$ & ns \\
\hline Very poor (n, \%) & $0(0 \%)$ & $0(0 \%)$ & - & \\
\hline Not applicable & I (I2.5\%) & I (7.7\%) & I (3.4\%) & ns \\
\hline
\end{tabular}

Notes: *Represents which variable is significant versus another with $P<0.05$. Bold $P$-values are statistically significant.

Abbreviations: DP, patients with major depression; OHIP-I4, oral health impact profile; PI, plaque index; GI, gingival index; OHI-S, simplified oral hygiene index; Pel, periodontal index; ns, not significant; SD, standard deviation.

The elevated frequency of periodontal problems among DP may be due, in part, to antidepressant therapy, apathy or, more generally, to the fact that people with mental illness are more likely to cancel or not attend appointments with dentists and/or oral hygienists. ${ }^{43}$ Moreover, it is wellknown that psychopharmacological treatments reduce the salivary flow rate that could contribute to the development of periodontal diseases. ${ }^{44}$ In addition, the severe impairment in self-care described in depression and anxiety can lead to oral health problems; ${ }^{13}$ however, in our sample, other variables than behavioral issues seem to determine a worse periodontal status among DP, since the two examined groups (DP and controls) presented similar hygienic habits.
Apart from hygiene, the association between depressive symptoms and higher lactobacillus counts or the association between depression and inflammation could offer an explanation of our findings. ${ }^{45,46}$ Inflammation plays a crucial role in the development of oral pathology too, so that polymorphisms of the genes involved in the immune response can lead to a higher susceptibility to periodontitis. ${ }^{47}$ In particular, the cyclooxygenase, that converts arachidonic acid to prostaglandins, exerts a fundamental role in the inflammatory process involved in the tissue destruction occurring in periodontitis. ${ }^{48-50}$ The same enzymatic way seems to be over-expressed in major depression. DP without other medical illnesses, in fact, present an increase 
of inflammatory markers both in serum and in the central nervous system. ${ }^{51}$ Hence, beyond the psychological explanation of the association between poor oral health and depression, there are biological factors that may contribute to the development of oral health problems among DP. The association between oral and mental health should not be underestimated, also considering that poor oral hygiene represents a risk factor for cardiovascular and kidney diseases, pulmonary infections, rheumatoid arthritis, and diabetes. ${ }^{52-56}$ Generally speaking, the link between oral and general health is well-known in literature ${ }^{57}$ Another interesting finding of this study pertains to the association between the severity of depression and periodontal health: DP with mild depression were more likely to present better dental index scores. More specifically, only few DP with severe depression presented an excellent PI, GI, PeI score, and a good OHI-S score. Compared to other studies, this paper highlights not only the link between affective symptoms and periodontal pathologies in general but also the importance of the severity of depression in terms of oral health outcomes. In addition, the analysis of our sample demonstrated a link between alexithymia and periodontal health: a considerable number of alexithymic patients presented, in fact, a poor PI and a fair PeI. Even in this case, inflammation could offer an explanation of the finding: the altered immune response found in depression has been demonstrated also in alexithymia. In particular, inflammatory markers such as high-sensitivity $\mathrm{C}$ reactive protein and interleukin- 6 were found to be significantly higher among alexithymic patients than in non-alexithymic ones. ${ }^{58}$ Along with major depression, alexithymia and personality disturbances seem to exert a role on the patient's periodontal health: in our sample, the strength of the association between depression and dental indexes was reduced by adjusting for these psychiatric variables. In fact, only the association between oral-health related quality of life (OHIP-14) and depression was confirmed and was not influenced by the presence of alexithymia and PDs. To the best of our knowledge, this is the first study examining the relationship between the severity of depression, alexithymia, and periodontal health. However, this study presents some limitations. Firstly, we did not use X-ray imaging, but a physical (dental) examination for the detection of oral health problems. Secondly, we did not consider the antidepressant therapy as a variable when evaluating the patient's periodontal status. Furthermore, the present study cannot infer causality. The relationship between depression and poor periodontal health may, in fact, be bidirectional: depression may affect oral health, behaviors, and quality of life but, conversely, people with dental problems may have a lower self-esteem and selfconfidence and these factors may lead to depression or worsen a current depressive episode.

\section{Conclusion}

Although the present study cannot ascertain causal association, it provides substantial evidence that oral and mental health are strictly linked. In particular, our study demonstrated a correlation between psychiatric variables and poor periodontal health. Longitudinal studies are necessary to clarify, in particular, the impact of depression and alexithymia on periodontal status. As a matter of fact, due to the high frequency of dental problems, patients suffering from mental illnesses should be referred to the oral health services for evaluation. Hence, in everyday clinical practice, the evaluation of the patient should imply special attention to general health.

\section{Acknowledgment}

The authors would like to thank all the participants to the study.

\section{Disclosure}

The authors declare that they have no competing interests.

\section{References}

1. Petersen PE, Bourgeois D, Ogawa H, Estupinan-Day S, Ndiaye C. The global burden of oral diseases and risks to oral health. Bull World Health Organ. 2005;83(9):661-669.

2. Nikias M. Oral disease and quality of life. Am J Public Health. 1985; 75(1):11-12.

3. Hollister MC, Weintraub JA. The association of oral status with systemic health, quality of life, and economic productivity. J Dent Educ. 1993; 57(12):901-912.

4. Stewart R, Weyant RJ, Garcia ME, et al. Adverse oral health and cognitive decline: the health, aging and body composition study. $J \mathrm{Am}$ Geriatr Soc. 2013;61(2):177-184.

5. Sheiham A, Watt RG. The common risk factor approach: a rational basis for promoting oral health. Community Dent Oral Epidemiol. 2000; 28(6):399-406

6. Petersen PE, Baehni PC. Periodontal health and global public health. Periodontol 2000. 2012;60(1):7-14.

7. Petersen PE, Yamamoto T. Improving the oral health of older people: the approach of the WHO Global Oral Health Programme. Community Dent Oral Epidemiol. 2005;33(2):81-92.

8. Tani H, Uchida H, Suzuki T, et al. Dental conditions in inpatients with schizophrenia: a large-scale multi-site survey. BMC Oral Health. 2012;12:32.

9. Edward KL, Felstead B, Mahoney AM. Hospitalized mental health patients and oral health. J Psychiatr Ment Health Nurs. 2012;19(5):419-425.

10. Preeja C, Ambili R, Nisha KJ, Seba A, Archana V. Unveiling the role of stress in periodontal etiopathogenesis: an evidence-based review. J Investig Clin Dent. 2013;4(2):78-83.

11. Lépine JP, Briley M. The increasing burden of depression. Neuropsychiatr Dis Treat. 2011;7(1):3-7. 
12. Luca M, Prossimo G, Messina V, Luca A, Romeo S, Calandra C. Epidemiology and treatment of mood disorders in a day hospital setting from 1996 to 2007: an Italian study. Neuropsychiatr Dis Treat. 2013;9: 169-176.

13. Anttila S, Knuuttila M, Ylöstalo P, Joukamaa M. Symptoms of depression and anxiety in relation to dental health behavior and self-perceived dental treatment need. Eur J Oral Sci. 2006;114(2):109-114.

14. Miyachi H, Wake H, Tamaki K, et al. Detecting mental disorders in dental patients with occlusion-related problems. Psychiatry Clin Neurosci. 2007;61(3):313-319.

15. Honkalampi K, Koivumaa-Honkanen H, Lehto SM, et al. Is alexithymia a risk factor for major depression, personality disorder, or alcohol use disorders? A prospective population-based study. J Psychosom Res 2010;68(3):269-273.

16. Luca M, Luca A, Calandra C. Psychomotor retardation and externally oriented thinking in major depression. Neuropsychiatr Dis Treat. 2013; 9:759-766.

17. Mattila AK, Pohjola V, Suominen AL, Joukamaa M, Lahti S. Difficulties in emotional regulation: association with poorer oral health-related quality of life in the general population. Eur J Oral Sci. 2012;120(3):224-231.

18. Pohjola V, Mattila AK, Joukamaa M, Lahti S. Dental fear and alexithymia among adults in Finland. Acta Odontol Scand. 2011;69(4):243-247.

19. Willemse BW, Postma DS, Timens W, ten Hacken NH. The impact of smoking cessation on respiratory symptoms, lung function, airway hyperresponsiveness and inflammation. Eur Respir J. 2004;23(3): 464-476.

20. Yoon YS, Oh SW, Baik HW, Park HS, Kim WY. Alcohol consumption and the metabolic syndrome in Korean adults: the 1998 Korean National Health and Nutrition Examination Survey. Am J Clin Nutr. 2004;80(1):217-224.

21. Trajković G, Starčević V, Latas M, et al. Reliability of the Hamilton Rating Scale for Depression: a meta-analysis over a period of 49 years. Psychiatry Res. 2011;30;189(1):1-9.

22. Hamilton M. A rating scale for depression. J Neurol Neurosurg Psychiatry. 1960;23:56-62.

23. Maier W, Buller R, Philipp M, Heuser I. The Hamilton Anxiety Scale: reliability, validity and sensitivity to change in anxiety and depressive disorders. J Affect Disord. 1988;14(1):61-68.

24. Hamilton M. The assessment of anxiety states by rating. $\mathrm{Br} \mathrm{J} \mathrm{Med}$ Psycol. 1959;32(1):50-55.

25. Bagby RM, Parker JD, Taylor GJ. The twenty-item Toronto Alexithymia Scale - I. Item selection and cross-validation of the factor structure. J Psychosom Res. 1994;38(1):23-32.

26. Taylor GJ, Bagby RM, Parker JD. Disorders of Affect Regulation: Alexithymia in Medical and Psychiatric Illness. Cambridge University Press; 1997.

27. Maffei C, Fossati A, Agostoni I et al. Interrater reliability and internal consistency of the structured clinical interview for DSM-IV axis II personality disorders (SCID-II), version 2.0. J Pers Disord. 1997;11(3): 279-284.

28. First MB, Gibbon M, Spitzer RL, Williams JBW, Benjamin LS. Structured Clinical Interview for DSM-IV Axis II Personality Disorders (SCID-II). Washington DC, American Psychiatric Press Inc; 1997.

29. Corridore D, Campus G, Guerra F, Ripari F, Sale S, Ottolenghi L. Validation of the Italian version of the Oral Health Impact Profile-14 (IOHIP-14). Ann Stomatol (Roma). 2014;4(3-4):239-243.

30. Slade GD, Spencer AJ. Development and evaluation of the Oral Health Impact Profile. Community Dent Health. 1994;11(1):3-11.

31. Franchignoni M, Giordano A, Brigatti E, Migliario M, Levrini L, Ferriero G. [Psychometric properties of the Italian version of the reduced form of the Oral Health Impact Profile (OHIP-14)]. G Ital Med Lav Ergon. 2010;32(3 Suppl B):71-78. Italian.

32. Mander CI, Mainwaring PJ. Assessment of the validity of two plaque indices. Community Dent Oral Epidemiol. 1980;8(3):139-141.

33. Silness J, Loe H. Periodontal disease in pregnancy. Response to local treatment. Acta Odontol Scand. 1966;24(6):747-759.
34. Poulsen S. Epidemiology and indices of gingival and periodontal disease. Pediatric Dentistry. 1981;3(Special issue):82-88.

35. Loe $H$. The gingival index, the plaque index and the retention index systems. J Periodontol. 1967;38(6):610-616.

36. Greene JC, Vermillion JR. The simplified oral hygiene index. J Am Dent Assoc. 1964;68:7-13.

37. Russell AL. The Periodontal Index. J Periodontol. 1967;38(6): S585-S591.

38. Adekoya Sofowora CA. The effect of poverty on access to oral health care in Nigeria. Nigerian Dental Journal. 2008;16:40-42.

39. Kebede B, Kemal T, Abera S. Oral health status of patients with mental disorders in southwest Ethiopia. PLoS One. 2012;7(6):e39142.

40. Clifton A, Tosh G, Khokhar W, Jones H, Wells N. Oral health 378 advice for people with serious mental illness. Schizophr Bull. 2011;37(3): 464-465.

41. Genco RJ, Ho AW, Grossi SG, Dunford RG, Tedesco LA. Relationship of stress, distress and inadequate coping behaviors to periodontal disease. J Periodontol. 1999;70(7):711-723.

42. Okoro CA, Strine TW, Eke PI, Dhingra SS, Balluz LS. The association between depression and anxiety and use of oral health services and tooth loss. Community Dent Oral Epidemiol. 2012;40(2):134-144.

43. Wieland B, Lau G, Seifert D, Siskind D. A partnership evaluation: public mental health and dental services. Australas Psychiatry. 2010;18(6): 506-511.

44. Wolff A, Zuk-Paz L, Kaplan I. Major salivary gland output differs between users and non-users of specific medication categories. Gerodontology. 2008;25(4):210-216

45. D'Mello DA. Are your patients depressed? Implications for dental practice. J Mich Dent Assoc. 2003;85(5):26-32.

46. Capuron L, Miller AH. Immune system to brain signaling: neuropsychopharmacological implications. Pharmacol Ther. 2011;130(2):226-238.

47. Yoshie H, Kobayashi T, Tai H, Galicia JC. The role of genetic polymorphisms in periodontitis. Periodontol 2000. 2007;43:102-132.

48. Noguchi K, Ishikawa I. The roles of cyclooxygenase- 2 and prostaglandin E2 in periodontal disease. Periodontol 2000. 2007;43:85-101.

49. Yen CA, Damoulis PD, Stark PC, Hibberd PL, Singh M, Papas AS. The effect of a selective cyclooxygenase-2 inhibitor (celecoxib) on chronic periodontitis. J Periodontol. 2008;79(1):104-113.

50. Daing A, Singh SV, Saimbi CS, Khan MA, Rath SK. Cyclooxygenase 2 gene polymorphisms and chronic periodontitis in a North Indian population: a pilot study. J Periodontal Implant Sci. 2012;42(5): 151-157.

51. Luca M, Luca A, Celia A, Calandra C. Prostaglandins pathway as a possible biological link between cancer and major depression. Current Angiogenesis. 2014;2(2):143-148.

52. de Oliveira C, Watt R, Hamer M. Toothbrushing, inflammation, and risk of cardiovascular disease: results from Scottish Health Survey. BMJ. 2010;340:c2451.

53. Fisher MA, Borgnakke WS, Taylor GW. Periodontal disease as a risk marker in coronary heart disease and chronic kidney disease. Curr Opin Nephrol Hypertens. 2010;19(6):519-526.

54. Paju S, Scannapieco FA. Oral biofilms, periodontitis, and pulmonary infections. Oral Dis. 2007;13(6):508-512.

55. Stamp LK, Khalilova I, Tarr JM, et al. Myeloperoxidase and oxidative stress in rheumatoid arthritis. Rheumatology (Oxford). 2012;51(10) 1796-1803.

56. Assumpção CR, Brunini TMC, Matsuura C, Resende AC, MendesRibeiro AC. Impact of the L-arginine-nitric oxide pathway and oxidative stress on the pathogenesis of the metabolic syndrome. Open Biochem J. 2008;2:108-115.

57. Reissmann DR, John MT, Schierz O, Kriston L, Hinz A. Association between perceived oral and general health. J Dent. 2013;41(7) 581-589.

58. Honkalampi K, Lehto SM, Koivumaa-Honkanen H, et al. Alexithymia and tissue inflammation. Psychother Psychosom. 2011;80(6):359-364. 


\section{Publish your work in this journal}

Neuropsychiatric Disease and Treatment is an international, peerreviewed journal of clinical therapeutics and pharmacology focusing on concise rapid reporting of clinical or pre-clinical studies on a range of neuropsychiatric and neurological disorders. This journal is indexed on PubMed Central, the 'PsycINFO' database and CAS, and is the official journal of The International Neuropsychiatric Association (INA). The manuscript management system is completely online and includes a very quick and fair peer-review system, which is all easy to use. Visit http://www.dovepress.com/testimonials.php to read real quotes from published authors.

\footnotetext{
Submit your manuscript here: http://www.dovepress.com/neuropsychiatric-disease-and-treatment-journal
} 